\title{
In Situ Localization of Proline in Oral Bacteria and on Lingual Epithelium
}

\section{DONALD K. MAC CALLUM}

Dental Research Institute, Departments of Oral Biology and Anatomy, University of Michigan, Ann Arbor, Michigan 48104, USA

During a study of proline utilization by mouse lingual epithelial cells (MacCallum, Anat Rec $175: 380,1973)$, some temporal aspects of the incorporation of the free amino acid by oral bacteria and the appearance of a proline-containing surface coat on oral epithelial cells were determined. Weanling C58 mice were injected intraperitoneally with 166 microcuries/gm of Lproline-2, $3 \cdot{ }^{3} \mathrm{H} \quad>40$ curies $\left./ \mathrm{m} M\right)$ and were killed 30 minutes or 1,4 , or 24 hours later.

Numerous bacteria demonstrated incorporated proline 30 minutes and one hour after injection (Fig 1). The mode of entrance of the free amino acid into the oral cavity is uncertain because the methods used in this study were designed to eliminate the chemical binding of free amino acids to tissue structures. Two obvious routes of entrance to the oral cavity are the salivary glands and gingival sulci. There is at least some fluid that contains free amino acids emanating from gingival sulci (WEINSTEIN ET AL, Periodontics 5: 161, 1967). Salivary gland fluid

Supported by USPHS Grants DE-02731 and DE-03393. Received for publication July 3, 1973. also contains free amino acids derived from the blood perfusing the glands (BURGEN, Physiology of Salivary Fluids, 1961, p 185).

One hour after injection of proline, the oral mucosal surface of the epithelium demonstrated a proline-containing compound (Fig 2). A likely source of this material was one of the salivary glands. Sreebny et al (J Biol Chem 246: 3879,1971 ) have demonstrated the presence of leucine-labeled, trichloracetic acid (TCA) insoluble protein in rat parotid saliva $20 \mathrm{~min}$ utes after administration of ${ }^{3} \mathrm{H}$ leucine. Subjacent epithelial cells did not produce this coating, since no labeled compounds were observed between the cells at this time.

A labeled amino acid administered intraperitoneally is rapidly carried to the oral cavity and used by oral bacteria. An epithelial surface coating containing the labeled isotope can be demonstrated within one hour after administration. The in situ demonstration of these phenomena by electron microscope radioautography should provide useful adjunctive data to current biochemical investigations.

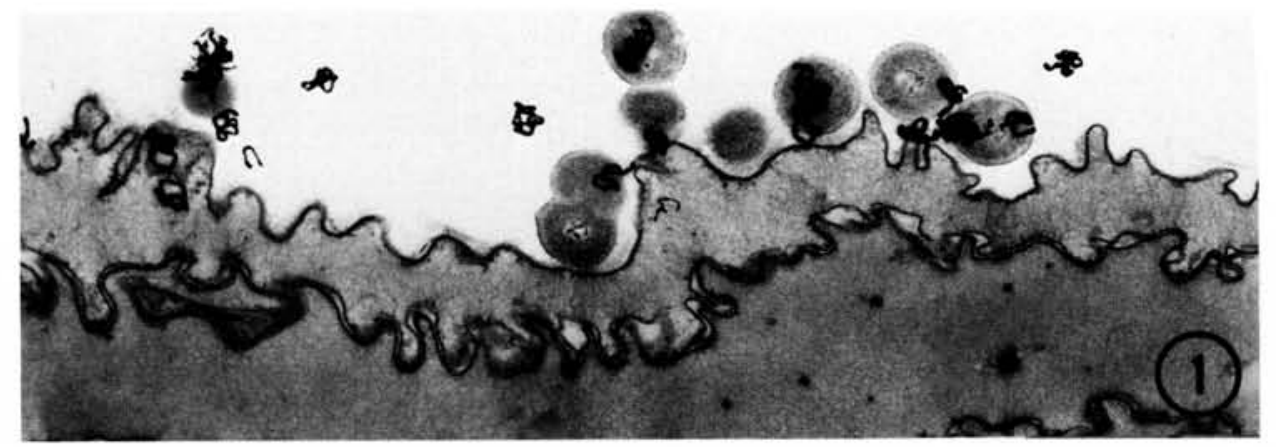

FIG 1.-Proline incorporated in bacteria adhering to lingual epithelium is indicated by silver grains over bacteria (orig mag $\times 20,000$, reproduced at $93 \%$ ).

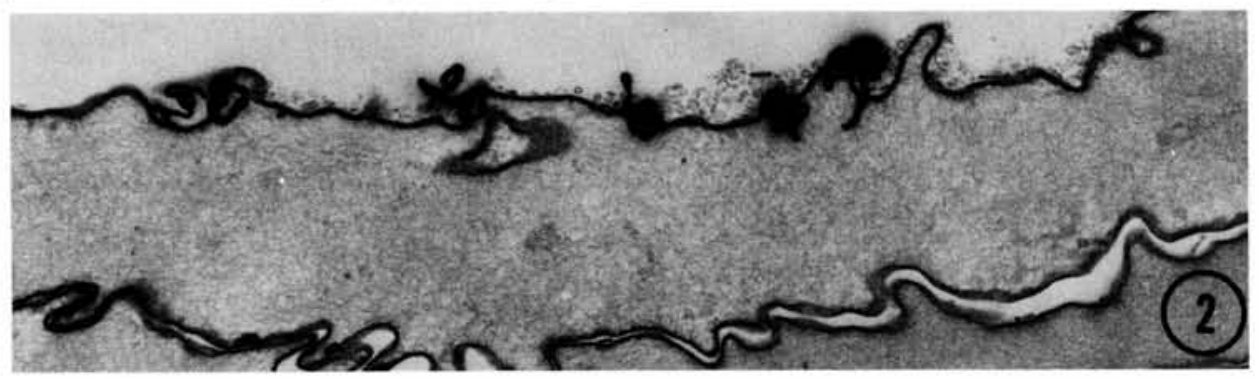

FIG 2.-Proline-containing epithelial surface coating, presumably of salivary gland origin, is shown one hour after injection of ${ }^{3} \mathrm{H}$ proline (orig mag $\times 40,000$, reproduced at $93 \%$ ). 